\title{
Analysis of Factors Affecting Technology Acceptance by Iranian Movie Producers
}

\author{
Dr. Mohammad Hossain Moshref Javadi \\ Faculty member, School of Management, University of Isfahan, Iran \\ Dr. Mohsen Allameh \\ Faculty member, School of Management, University of Isfahan, Iran \\ Arash Zare \\ Graduate Student of Management, University of Isfahan, Iran
}

Accepted: January 12, 2012 Published: February 06, 2012

Doi:10.5296/ijhrs.v2i1.1360

URL: http://dx.doi.org/10.5296/ijhrs.v2i1.1360

\begin{abstract}
Since investment on cinematic technologies imposes excessive costs on authorities, acceptance of these technologies among its users has an important role in their success and final efficiency. The purpose of this study was to analyze factors influencing on acceptance of technology among Tehran cinematic artists. In this study, at first, by collecting information from the library, determinant variables of usage of new technologies were specified. On this basis, in addition to the variables of model of acceptance of technology, social influence, resistance to change and self- efficacy were studied. In next stage, for surveying the effect of studied components, closed- end 27- items questionnaire was used for collecting data. The measurement tools in this study were the established questionnaire made of a technology acceptance model. The number of sample was determined equal to 211 according to the preliminary study that samples included Tehran cinematic actors. Based on the results, all variables, except for resistance to change and self- efficacy of computer that had meaningful difference less than average, other had meaningful difference more or equal to average. Mean difference of attitude toward usage of technology and of social influence was meaningful in different graduate ranges and mean of other factors shows no meaningful difference in different graduate ranges. All assumptions were confirmed in 5\% meaningful level.
\end{abstract}

Keywords: Technology Acceptance Model, Cinema, Social Influence, Resistance to Change, Self- Efficacy. 


\section{Introduction}

In spite of abundant investments that are performed in IT systems, there is not exact information about these investments and their rate of return. In such case, organizations could not achieve their expected efficiency and effectiveness from investment in this area. Accordingly, they encounter with productivity puzzle in usage of this technology. At the same time in other studies during 1990s performed, evidences were observed from positive efficiency in investments is such area. Therefore, this question is set forth that why and when such investments in IT have efficiency? This study of procedure points out the cost effectiveness of success in IT usage. When new technology enters into the organization, measuring return rate of such investments becomes necessary. By increasing the usage of new technology, the requirement of study about factors influencing on their usage, was changed to an important affair for researcher and actors in this area (Yi \& Hwang 2003). Since investments in cinematic technologies imposes excess costs on the organizations acceptance of these technologies among their users has an important role in its efficiency and success. This study focuses on whether such technologies were accepted and it also surveys the factors influencing on its acceptance. In fact, it surveys the level and tendency toward usage and the factors that influence on it. It also tests the level of social influence factors, resistance toward change and self- efficacy plus surveys their effect on given variables.

\section{Literature Review}

The advent of cinema and its technology was begun from park yards until the cinema industry changes to one of the most costing industry, the most interesting and noble art. The cinema has not begun with kind of explosion. Not any special event can be mentioned that distinguishes between cinema age and age before it. The advent of cinema is a continuous process and flow that has begun by testes and primary tools that their purpose was to show pictures as consecutive ones. This visual arrangement considered as a toy which was changed to a complex machine that introduced subjective reality as movement. The advent of cinema requires arrangements that inventors solved such problem. After providing arrangements necessary for advent of cinema, the different kinds of film- taking cameras were appeared in America, England, France and Germany. These machines had different names such as Kinetos cope, Bioscope, Vitascope, Cine meat, where these graph machines did excellent work, ie: They showed black- white pictures of living persons in real world. The efforts of scientists and inventors for finding these machines obliged us to accept cinema as beginning of such art, but moving pictures might be remain in one- minute views stage, in extent to which they were related to the inventors. At the same time, scientific aspect of cinema was important for them, but they did not pay too much attention to art and creativity behind these machines. The primary films were very simple according to the content and form, but they were only film- taking from life. Primary viewers watched natural views such as attacking wars on coast, quick movement of machines in streets, entering train into station and even people walking in the sun, but because of these primary but magic pictures, cinema was distributed around the world, evolved complex technology and changed to important industry. 


\section{MInstitute Macrink $_{\text {Ins }}$}

The industry is not only used as a hobby, but it can be used for other purposes such as training, scientific search and so on. With these features, artists, scientists and politicians also became interested on it. By this way, inventors continued to develop and invent in domain of cinema by developing cinema in the world and work on its popularity. These discoveries were used by cinematic traders as well. Really, inventor, artist and trader compose three angles of a triangle. They cannot work without each other and viewers who help the cinema stability. In previous studies, users' attitude toward acceptance of new technology has an important role in its success. Succi and walter, and others try to find factors influencing on individual acceptance of technology in order to improve its usage. There are different models originating to sociology, psychology and information systems.

In this study, technology acceptance model was used for determining the factors that have an important effect on technology acceptance.

\section{Model Used:}

Diagram 1: Technology Acceptance Model (Davice and other 1989).

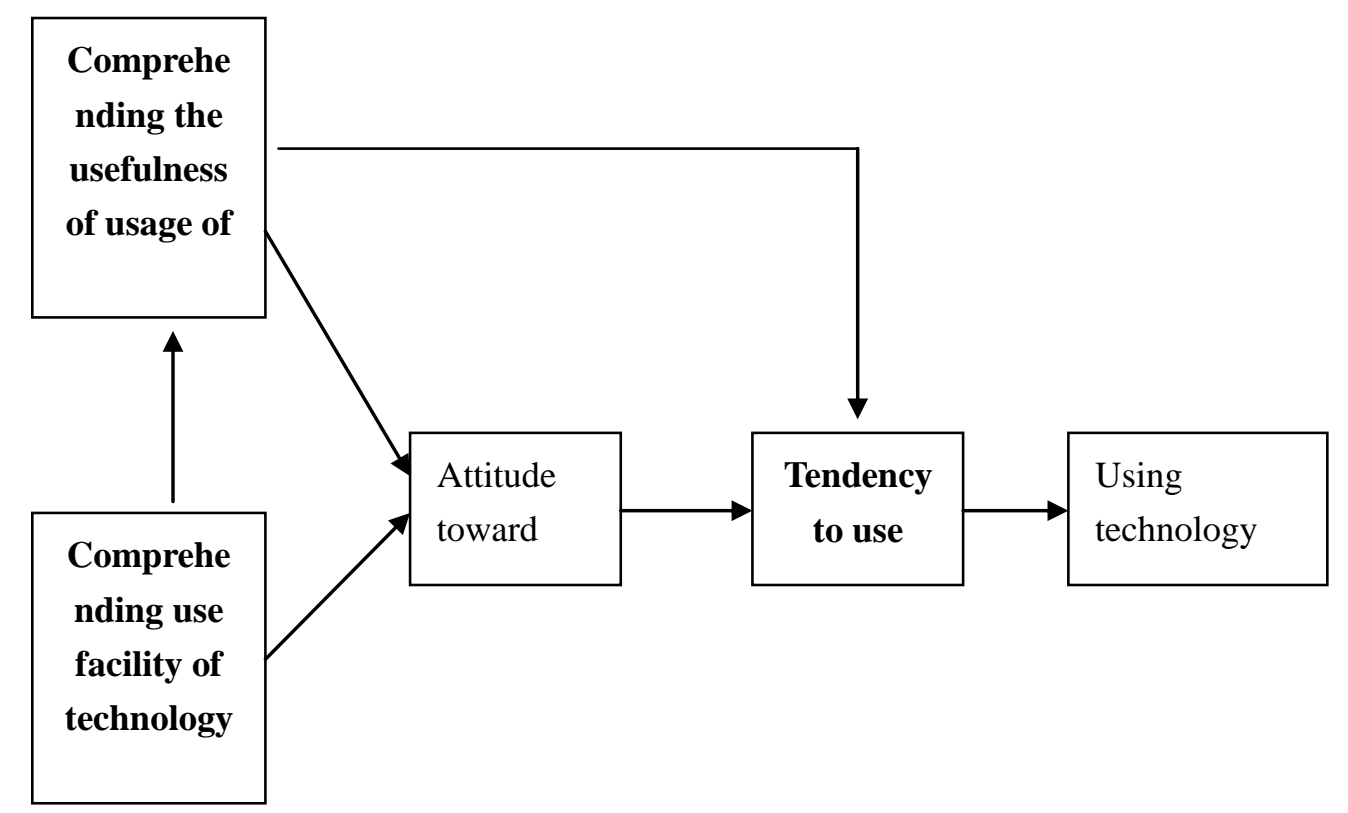

This model is the most commonly used model that is applied to acceptance of technology. The given model assumes that user's conception from use facility of new technology and its usefulness has effect on users' attitude toward usage of new technology. Usefulness conception refers to this persons' belief whether usage of system can promote and improve its performance. While conception of usage facility refers to extent which person believes usage of system is easy. These all create this attitude in person that causes the person to use new 
technology. This theory is based on reasoned action theory (RAT). It is a psychological theory that states that person's actions are specified on their tendency to do it. In this theory, tendency and aim is considered as a determinant factor of behavior that is influenced by attitude (toward doing behavior) and mental orders. TAM is an instrument for experimental studies and its ability to explain tendency and attitude toward technology usage which is better than TRA and TPB. Many scientists added other variables to TAM model.

In this study, the factors added to this model as external variable include: social influence, resistance degree to change and self- efficacy in technology usage.

\section{Diagram 2: conceptual model of search}

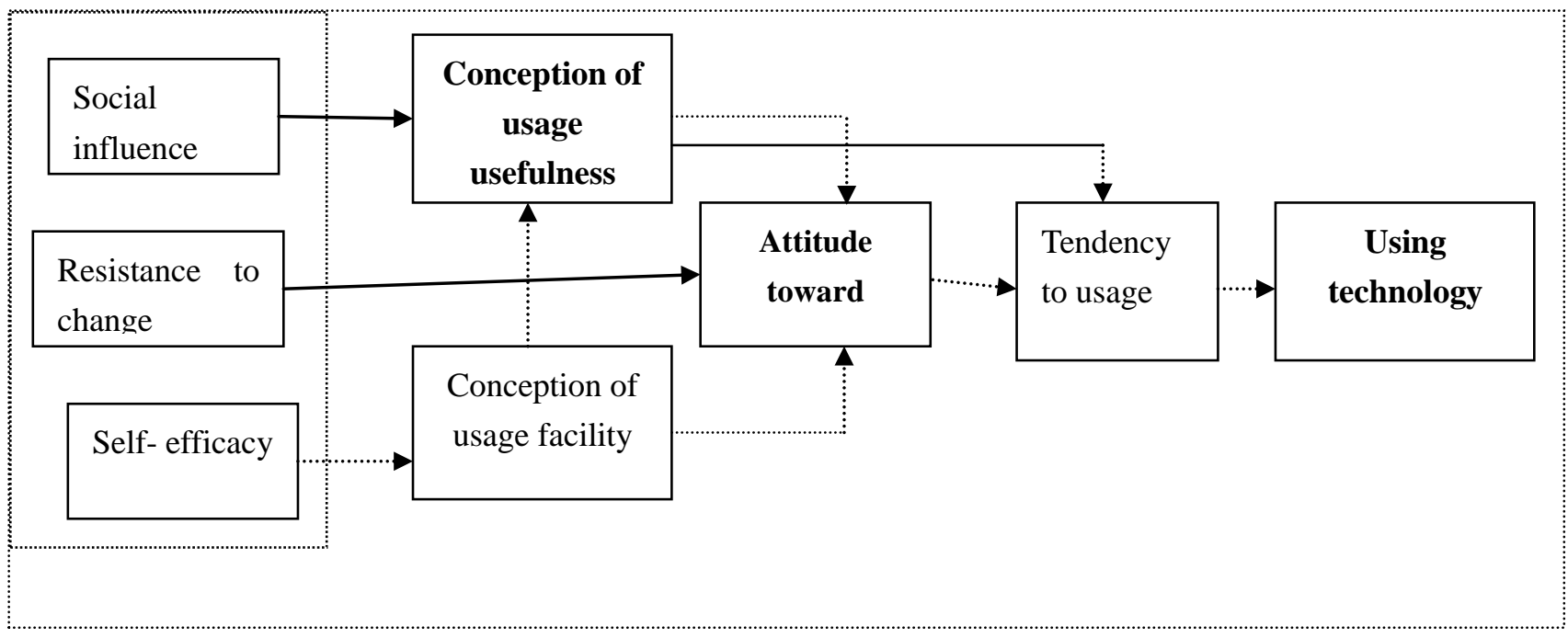

\section{Research hypothesis}

1. Social influences effect on conception of usefulness of new technologies among cinematic actors.

2. Resistance to change influences on attitude toward usage of new technologies among Tehran cinematic actors.

3. Self- efficacy influences on conception of usage facility of new technologies among Tehran cinematic actors.

4. Conception of usage facility influences on conception of usefulness of new technologies among Tehran cinematic actors.

5. Usage facility conception influences on attitude toward usage of new technologies among Tehran actors.

6. Usage usefulness conception influences on usage of new technologies among Tehran actors.

7. Usage usefulness conception influences on usage of new technologies among Tehran actors. 
8. Attitude toward usage influences on tendency toward usage of new technologies among Tehran cinematic actors.

9. Tendency toward usage influences on new technologies among Tehran cinematic actors.

\section{Methodology of research}

In this study, firstly determinant variables of using new technologies were specified by collecting librarian sources. On this basis, besides variables of technology acceptance model, social influence, resistance to change and self- efficacy were studied. In next stage, closedend 27 items questionnaire was used for collection of data. Specialized items of questionnaire include composition of items of standard questionnaire related to factors of technology acceptance model and other effective factors. With regard to the number of statistical of actors union and according to standard deviation obtained from primary pilot and use of limited society formula, 235 were selected as statistical samples. in which 211 acceptable questionnaires were returned.

\section{Analysis of data}

\section{First test}

In this section, attitude toward usage technology and conception of usefulness toward usage and facility conception of usage were considered as independent variable and tendency toward usage as dependent variable. Table 1 shows the results from variance test. As observed in first section, because sign is less than $5 \%, \mathrm{H}_{0}$ is rejected and $\mathrm{H}_{1}$ is accepted, so hypothesis of being linear relation between variables and tendency toward usage is confirmed. According to data of second section, because sign of test is fixed and regression coefficients of attitude and usefulness conception variables are less than $5 \%$, the hypothesis of equality of coefficients of these variables and fixed value with zero value is rejected. For comparing the effects of two variables presented in the regression model on dependent variable of tendency toward usage of technology, table 1 shows standardized coefficients (beta).

\section{Table 1.}

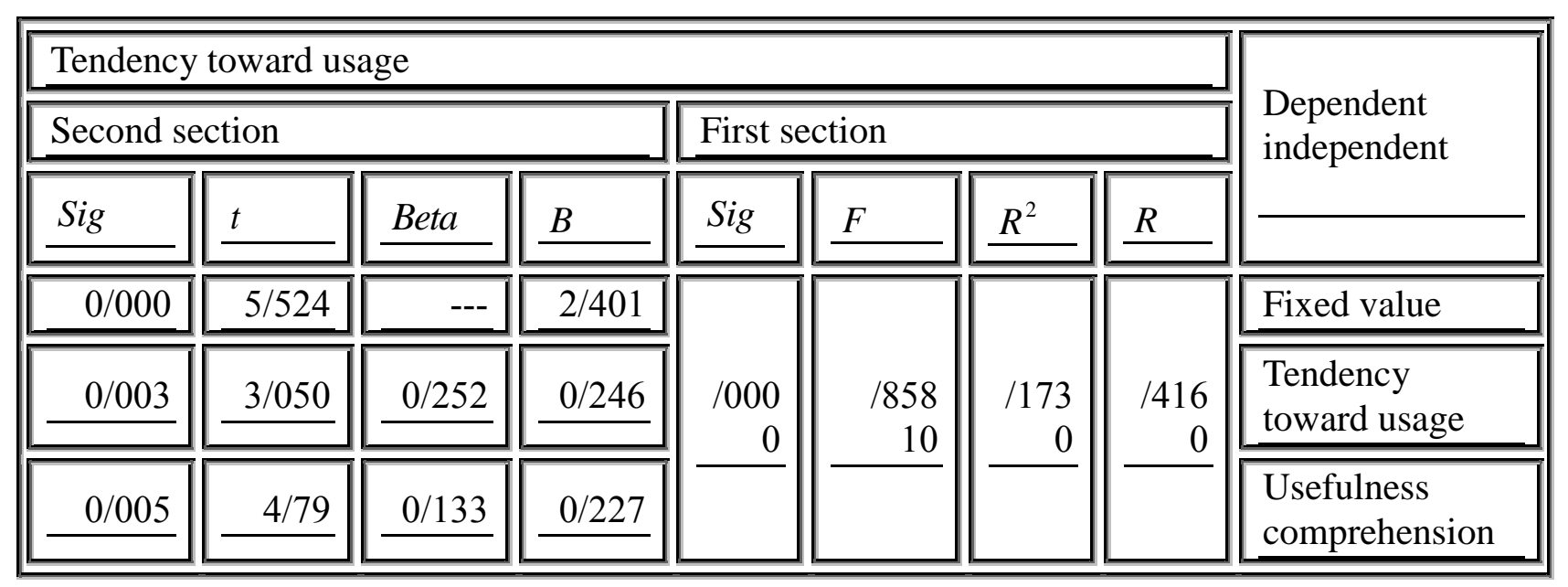




\section{Second test}

In this section, usefulness comprehension, resistance toward change, and usage facility comprehension variables are considered as independent variable and attitude toward usage as dependent variable.

Table 2 shows the results of variance test. As observed in the first section, because sign is less than $5 \%, \mathrm{H}_{0}$ is rejected and $\mathrm{H}_{1}$ is accepted. So hypothesis of being linearly related with variables is confirmed. According to data of second section, since sign of test is fixed value and usefulness comprehension, resistance to change and usage facility comprehension variables regression coefficients is less than $5 \%$, so equality of coefficients of these variables and fixed value with zero value is rejected. For comparing the effects of three variables presented in the regression model on attitude toward usage dependent variable, column of beta shows that facility comprehension and resistance toward change and usefulness comprehension have the highest effect.

Table 2.

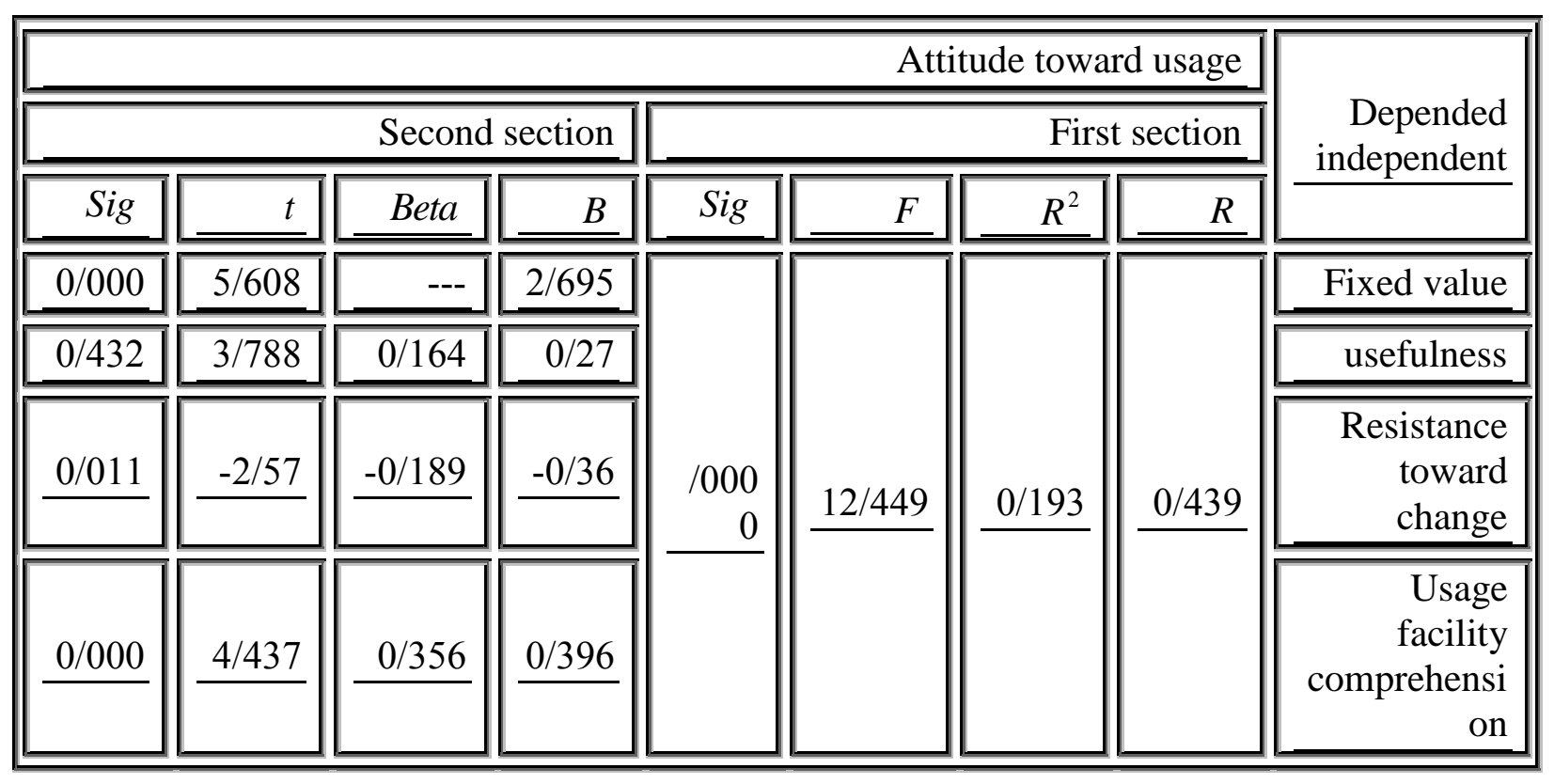

\section{Third test}

In this section, usage facility comprehension and social influence variable are considered as independent variable and usefulness comprehension as dependent variable.

Table 3 shows the results of variance test. As observed in first section, because sign is less than $5 \%, \mathrm{H}_{0}$ is rejected and $\mathrm{H}_{1}$ is accepted. So it is confirmed that there exist a linearly relationship between the variables. According to data of second section, sign of test is fixed value and social influence and usage facility comprehension variables regression coefficients are less than 5\%, so equality of these variables coefficients and fixed value with zero value is rejected. 
Table 3.

\begin{tabular}{|c|c|c|c|c|c|c|c|c|}
\hline \multicolumn{8}{|c|}{ Tendency toward usage } & \multirow{3}{*}{$\begin{array}{r}\text { Depended } \\
\text { independent }\end{array}$} \\
\hline \multicolumn{4}{|c|}{ First section } & \multicolumn{4}{|c|}{ First section } & \\
\hline Sig & $t$ & Beta & $B$ & Sig & $F$ & $R^{2}$ & $R$ & \\
\hline $0 / 018$ & $2 / 388$ & --- & $1 / 119$ & \multirow{3}{*}{$0 / 000$} & \multirow{3}{*}{$16 / 89$} & \multirow{3}{*}{$0 / 245$} & \multirow{3}{*}{$0 / 495$} & Fixed value \\
\hline $0 / 000$ & $3 / 946$ & $0 / 312$ & $0 / 343$ & & & & & $\begin{array}{r}\text { Usage } \\
\text { facility } \\
\text { comprehensi }\end{array}$ \\
\hline 0/001 & $3 / 33$ & $0 / 259$ & $0 / 290$ & & & & & $\begin{array}{l}\text { Social } \\
\text { influence }\end{array}$ \\
\hline
\end{tabular}

\section{Fourth test}

In this section, self- efficacy variable and usage facility comprehension variable are considered as independent and dependent variable respectively.

Table 4 shows the results of variance test. As observed in the first section, because sign is less than $5 \%, \mathrm{H}_{0}$ is rejected, $\mathrm{H}_{1}$ is accepted, so it is confirmed that there exist linearly relationship between variables. According to data of second section, since sign of self- efficacy variable regression coefficient is less than $5 \%$, so it is rejected that coefficients of these variables are equal and fixed value, so sign is larger than $5 \%$, it is not entered to the equation.

Table 4.

\begin{tabular}{|c|c|c|c|c|c|c|c|c|}
\hline \multicolumn{8}{|c|}{ Tendency toward usage } & \multirow{3}{*}{$\begin{array}{c}\text { Depended } \\
\text { independent }\end{array}$} \\
\hline \multicolumn{4}{|c|}{ First section } & \multicolumn{4}{|c|}{ First section } & \\
\hline Sig & $t$ & Beta & $B$ & Sig & $F$ & $R^{2}$ & $R$ & \\
\hline $0 / 497$ & $-0 / 68$ & --- & $-0 / 313$ & \multirow{2}{*}{$0 / 000$} & \multirow{2}{*}{$31 / 473$} & \multirow{2}{*}{$0 / 377$} & \multirow{2}{*}{$0 / 255$} & Fixed value \\
\hline $0 / 004$ & $2 / 93$ & $0 / 255$ & $0 / 5$ & & & & & Self- efficacy \\
\hline
\end{tabular}




\section{Fifth test}

In this section, tendency toward usage and exact usage are considered as in dependent and dependent variables respectively.

Table 4 shows the results of variance test. As observed in first section, the sign is less than $5 \%, \mathrm{H}_{0}$ is rejected and $\mathrm{H}_{1}$, is accepted, so it is confirmed that there exist linearly relationship between variables. According to data of second section, sign of tendency toward usage variable regression coefficients test with zero value is less than $5 \%$, so it is rejected that coefficients of these variables whit zero value are equal. About fixed value, so sign is larger than $5 \%$, and it is not entered to the equation.

Table 5

\begin{tabular}{|c|c|c|c|c|c|c|c|c|}
\hline \multicolumn{8}{|c|}{ Tendency toward usage } & \multirow{3}{*}{$\begin{array}{r}\text { Depended } \\
\text { independent }\end{array}$} \\
\hline \multicolumn{4}{|c|}{ First section } & \multicolumn{4}{|c|}{ First section } & \\
\hline Sig & $t$ & Beta & $B$ & Sig & $F$ & $R^{2}$ & $R$ & \\
\hline $0 / 358$ & $0 / 59$ & --- & $-0 / 415$ & \multirow{2}{*}{$0 / 000$} & \multirow{2}{*}{$41 / 473$} & \multirow{2}{*}{$0 / 425$} & \multirow{2}{*}{$0 / 652$} & Fixed value \\
\hline 0/004 & $2 / 43$ & $0 / 652$ & $0 / 5$ & & & & & $\begin{array}{l}\text { Usage } \\
\text { tendency }\end{array}$ \\
\hline
\end{tabular}

\section{Discussion and conclusion}

1. Social influence effects on usefulness of new technologies among cinematic actors.

2. According to results of this study, this hypothesis is confirmed at $5 \%$ meaningful level. So social influence has a positive and direct effect on usefulness of new technologies among actors. The regression coefficient value is $0 / 259$ for this hypothesis. It means that usefulness will be better and more suitable by increasing social influence. Also one unit of change in social influence creates 0/259 unit of change in usefulness of new technology.

3. Resistance to change has an effect on attitude toward usage of new technologies among cinematic actors.

According to results of this study, this hypothesis is confirmed at 5\% meaningful level. So resistance to change has a negative and converse effect on attitude toward usage of new technologies among cinematic actors. The regression coefficient value is $-0 / 189$ for this hypothesis. It means that attitude toward usage of new technologies will be better and more suitable by increasing resistance toward change. Also one unit of change in resistance toward change creates $-0 / 189$ unit of change toward usage of new technologies.

4. Self- efficacy has an effect on facility comprehension of usage of new technologies among cinematic actors.

According to the results of this study, this hypothesis is confirmed at 5\% meaningful level. 
So self- efficacy has a positive and direct effect on facility conception of usage of new technologies between cinematic actors. Regression coefficient is $0 / 225$ for this hypothesis. It means that facility conception of usage of new technologies will be more suitable by increasing self- efficacy. Also one unit of change in self- efficacy creates 0.255 unit of change in facility conception of usage of new technologies.

5. Usage facility conception has an effect on usefulness of new technologies among cinematic actors.

According to the results of this study, this hypothesis is confirmed at 5\% meaningful level. So usage facility conception has a positive and direct effect on usefulness of new technologies between cinematic actors. The regression coefficient value is $0 / 312$ for this hypothesis. It means that usefulness of new technology will be more suitable by increasing usage facility comprehension. Also one unit of positive change in usage facility comprehension creates $0 / 312$ unit of change in usefulness of technology.

6. Usage facility comprehension has an effect on attitude toward usage of new technologies among cinematic actors.

According to the results of this study, this hypothesis is confirmed at 5\% meaningful level. So usage facility comprehension has positive and direct effect on attitude toward usage of new technologies. Regression coefficient value is $0 / 356$ for this hypothesis. It means that attitude toward usage will be better and more suitable by increasing usage facility conception. Also one unit of change in facility conception creates 0/356 unit of change in attitude toward usage.

7. Usage usefulness comprehension has an effect on attitude toward usage of new technologies among cinematic actors.

According to the result of this study, this hypothesis is confirmed at 5\% meaningful level. So usage usefulness comprehension has positive and direct effect on attitude toward usage of new technologies between cinematic actors. Regression coefficient value is 0/164 for this hypothesis it means that attitude toward usage will be better and more suitable by increasing usefulness comprehension. Also one unit of change in usefulness conception creates $0 / 133$ unit of change in tendency toward usage of technology.

8. Attitude toward usage has an effect on tendency toward usage of new technologies among cinematic actors.

According to the results of this study, this hypothesis is confirmed at 5\% meaningful level. So attitude toward usage has a positive and direct effect on tendency toward usage of new technologies between cinematic actors. Regression coefficient value is $0 / 652$ for this hypothesis. It means that by increasing tendency toward usage, actors exhibit more usage. Also one unit of change in tendency toward usage creates 0/652 unit of change in exact usage. The high value of regression coefficient shows the importance of creating tendency in staff for cinematic actors.

\section{Limitation of study}

1. This study was performed in given time limit among Tehran cinematic actors and it points to analysis of factors influencing on technology acceptance in this time limit. 
2. The results of this study are used for generalizing to Tehran cinematic actors and it must be given care in other usages.

\section{Proposals based on findings of study}

1. Since governance level of all variables except for self- efficacy was higher than average level, it can be said that cinematic actors are not in suitable level in light of such factors, however since these factors have considerable coefficients in given relations, improving more these factors by enhancing attitude level and tendency toward usage of new technologies can increase technology acceptance level among cinematic actors.

2. Researchers, by finding origin of low self- efficacy, try to eliminate it. The researchers' procedures include: paying more attention to films requiring suitable visual and hearing technologies, cinematic advertisement emphasizing contents of films, structure and film technology, providing and producing cinematic technology inside country in order to reduce costs and to spread this technology, investing on technologies and using them in government films by states.

3. Organizational motives are lower than average level in studied society, so it is necessary to allocate organizational motives.

4. Increasing and enhancing educational level of cinematic actors for encouraging them to use new technology.

5. Introducing training workshop in order to provide necessary self- efficacy for using technologies.

6. Paying more attention to social influence for enhancing suitable attitude of staff to use technology.

7. Justifying investors, private and public sources with respect to analyzed factors of technology acceptance before producing each film for investment of necessary technology in such film.

8. Producing television programs or short films which consider using required technologies in Iranian films among Tehran cinematic actors and to accept it by Iranian audiences. 


\section{Al Macrothink}

\section{References}

Davis, F. D. (1989)." Perceived Usefulness, Perceive Ease of Use, and User Acceptance Information Technology". MIS Quarterly. Vol. 13, pp .319-339.

Dehning, B., and V. J. Richardson.( 2002). Returns on investment in information technology: A research synthesis. Journal of Information Systems, Vol. 16, No. 1, PP. 7-30.

Fishbein,M. \&Ajzen,I. (1975)."Beliefs, attitude, intension and behavior: an introduction to theory and research reading". MA: Addison Wesley.

Santos, Brian Dos, and Lyle Sussman, (2000), Improving the return on IT investment: The productivity paradox. International journal of information management, Vol. 20, pp. 429-440

Succi, M.J., Walter, Z.D., (1999). "Theory of users acceptance of information technologies: an examination of health care professionals". Proceeding of the 32nd Hawaii international conference on system Science (HICSS), pp. 1-7.

Venkatesh, V. Morris, M.G., Davis, G.B., \& Davis, F.D.(2003) “infuser acceptance of formation technology: toward a unified view”. MIS Quarterly. Vol. 27, No. 3, pp.425-478 .

Yi , Mun Y. and Hwang, Yujong, (2003)." Predicting the use of web-based information systems: self-efficacy, enjoyment, learning goal orientation, and the technology acceptance model”. Int. J. Human-Computer Studies, Vol. No., PP. 431-449. 